Case Report

\title{
Novel Variant in CLDN16: A Further Step in the Diagnosis of Familial Hypomagnesemia with Hypercalciuria and Nephrocalcinosis-A Case Report
}

\author{
Gopal Narang ${ }^{1, *}$, Tim Shimon ${ }^{2}$, Jonathan Moore ${ }^{1}$, Megan Hager ${ }^{3}$, Filippo Pinto e Vairo ${ }^{4,5}$, , Karen Stern ${ }^{1}$, \\ Mira Keddis ${ }^{6}$ and Mitchell Humphreys ${ }^{1}$ \\ 1 Department of Urology, Mayo Clinic, Phoenix, AZ 85054, USA; Moore.Jonathan@mayo.edu (J.M.); \\ Stern.Karen@mayo.edu (K.S.); Humphreys.Mitchell@mayo.edu (M.H.) \\ 2 Creighton Medical School, Omaha, NE 68178, USA; TimShimon@creighton.edu \\ 3 Department of Clinical Genomics, Mayo Clinic, Rochester, MN 55902, USA; Hager.Megan@mayo.edu \\ 4 Center for Individualized Medicine, Mayo Clinic, Rochester, MN 55902, USA; vairo.filippo@mayo.edu \\ 5 Department of Clinical Genomics, Mayo Clinic, Phoenix, AZ 85054, USA \\ 6 Department of Nephrology, Mayo Clinic, Phoenix, AZ 85054, USA; keddis.mira@mayo.edu \\ * Correspondence: Narang.Gopal@mayo.edu
}

\section{check for}

updates

Citation: Narang, G.; Shimon, T.; Moore, J.; Hager, M.; Pinto e Vairo, F.; Stern, K.; Keddis, M.; Humphreys, M. Novel Variant in CLDN16: A Further Step in the Diagnosis of Familial Hypomagnesemia with Hypercalciuria and Nephrocalcinosis-A Case Report. Uro 2021, 1, 76-81. https:/ /doi.org/ 10.3390/uro1030011

Academic Editor: Tommaso Cai

Received: 1 June 2021

Accepted: 25 June 2021

Published: 30 June 2021

Publisher's Note: MDPI stays neutral with regard to jurisdictional claims in published maps and institutional affiliations.

Copyright: (c) 2021 by the authors. Licensee MDPI, Basel, Switzerland. This article is an open access article distributed under the terms and conditions of the Creative Commons Attribution (CC BY) license (https:/ / creativecommons.org/licenses/by/ $4.0 /)$.

\begin{abstract}
Familial hypomagnesemia with hypercalciuria and nephrocalcinosis (FHHNC) is a rare tubulopathy characterized by renal loss of calcium and magnesium leading to progressive renal failure. The disorder is caused by variants to the tight junction proteins claudin-16 and -19 . While rare, this disorder causes a significant burden to patients based on its clinical manifestations of various electrolyte abnormalities, nephrocalcinosis, and early progression to renal failure. In this report we describe the diagnosis of a novel variant of CLDN16 which clinically presented with severe hypomagnesemia, hypocalcemia, nephrocalcinosis, and renal failure.
\end{abstract}

Keywords: FHHNC; CLDN16; nephrocalcinosis; nephrolithiasis

\section{Introduction}

Familial hypomagnesemia with hypercalciuria and nephrocalcinosis (FHHNC) is a rare autosomal recessive disorder caused by pathogenic variants in CLDN16 and CLDN19, which encode the tight junction proteins claudin-16 and -19 [1-3]. Defects in these proteins lead to defective paracellular reabsorption of magnesium and calcium in the thick ascending limb of the loop of Henle and subsequent hypomagnesemia and hypercalciuria [4]. Sequela of these electrolyte abnormalities are responsible for FHHNC's clinical presentation, characterized by polyuria, urinary tract infections, nephrocalcinosis, and chronic kidney disease (CKD) with early progression to renal failure [5]. Biochemical findings and clinical features are suggestive of FHHNC, but genetic testing has been increasingly used in a confirmatory role.

The understanding of the pathophysiology of FHHNC continues to evolve with approximately 130 cases reported since its initial description in the 1970s. Here we add to that fund of knowledge with a case report of an individual with symptomology typical of FHHNC, with a novel variant of uncertain significance (VUS), and a pathogenic variant in CLDN16.

\section{Case Report}

A 43-year-old male with a longstanding history of nephrolithiasis was transferred to our hospital in late 2017. His first stone episode was at the age of 10 years and since then he has passed 'hundreds to thousands of stones'. His past medical history is notable for gout, recurrent urinary tract infections (UTI) and CKD stage III, and creatinine (Cr) 1.7 (eGFR $53 \mathrm{~mL} / \mathrm{min} / 1.73 \mathrm{~m}^{2}$ ), stable over the past 13 years. He had no other hormonal or 
metabolic disorders. His past surgical history included multiple failed treatments with extracorporeal shockwave lithotripsy. He reported no family history of nephrolithiasis or renal disease. Prior to presentation, he was managed on hydrochlorothiazide (HCTZ) $12.5 \mathrm{mg}$ daily, potassium chloride $15 \mathrm{mEq}$ twice a day, colchicine $0.6 \mathrm{mg}$ twice a day, and prophylactic trimethoprim/sulfamethoxazole (dose unknown).

He was transferred to the Mayo Clinic due to severe electrolyte abnormalities in October 2017. His labs were notable for a Cr of 1.95 (eGFR $49 \mathrm{~mL} / \mathrm{min} / 1.73 \mathrm{~m}^{2}$ ), potassium of $2.6 \mathrm{mmol} / \mathrm{L}$, bicarbonate $26.5 \mathrm{mmol} / \mathrm{L}$, magnesium of $0.5 \mathrm{mg} / \mathrm{dL}$, and calcium of $5.2 \mathrm{mg} / \mathrm{dL}$. His parathyroid hormone (PTH) was $96.3 \mathrm{pg} / \mathrm{mL}$, vitamin D $27 \mathrm{ng} / \mathrm{mL}$, and 1,25-dihydroxy vitamin D $47 \mathrm{pg} / \mathrm{mL}$. Of note, the patient had had a computational tomography of this neck in the past to evaluate his elevated PTH. This showed no parathyroid adenomas or masses. CT of the abdomen and pelvis during admission was notable for extensive calcifications of the medullary regions of both kidneys consistent with nephrocalcinosis and an obstructing $1 \mathrm{~cm}$ right renal pelvis stone (Figure 1). The patient had a ureteral stent placed for the obstructing stone and his electrolytes were normalized with supplementation. He was discharged on magnesium oxide $800 \mathrm{mg}$ four times a day, calcium carbonate $1000 \mathrm{mg}$ three times a day, amiloride $5 \mathrm{mg}$ daily, colchicine $0.6 \mathrm{mg}$ twice a day, and allopurinol $100 \mathrm{mg}$ daily, and advised to continue HCTZ $12.5 \mathrm{mg}$ daily and potassium chloride $15 \mathrm{mEq}$ twice a day.

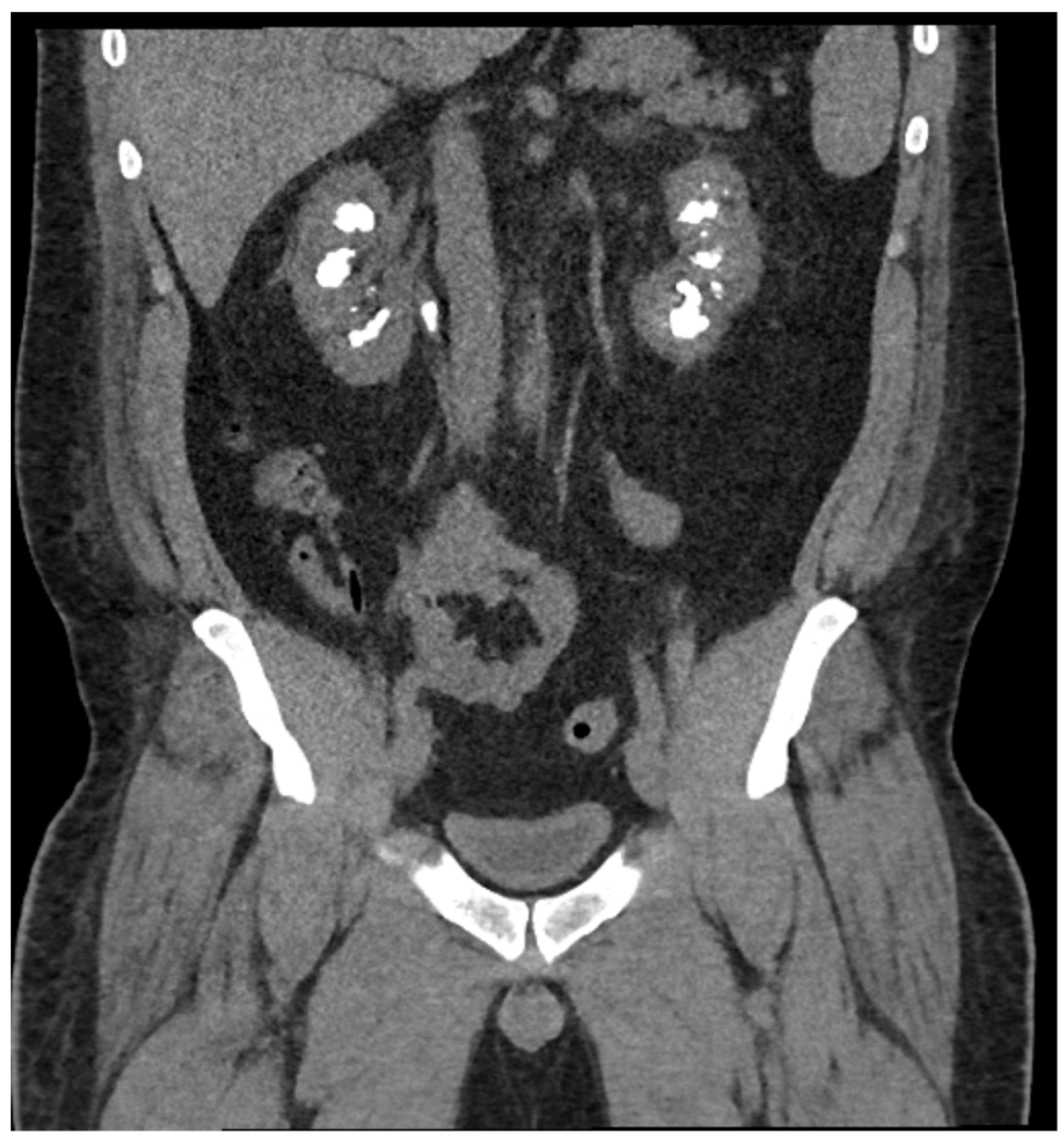

Figure 1. CT scan on presentation demonstrating bilateral large volume stone burden and an obstructing $1 \mathrm{~cm}$ right ureteropelvic junction stone. Burden of stone disease consistent with nephrocalcinosis.

He underwent a standard (30 fr) right percutaneous nephrolithotomy in December 2017. This demonstrated a large right renal pelvis stone as well as numerous stones in the collecting system and emanating from the parenchyma. Given the extensive stone 
burden, he was unable to be rendered visually stone-free. Stone analysis revealed a mixed composition stone, $70 \%$ calcium phosphate (apatite), $20 \%$ calcium oxalate monohydrate, and $10 \%$ calcium oxalate dehydrate.

The patient underwent a metabolic urine evaluation in January 2018. This demonstrated hypercalciuria, severe hypocitraturia, elevated urinary $\mathrm{pH}$, and adequate urinary volume (Table 1). The patient was started on chlorthalidone $12.5 \mathrm{mg}$ daily in lieu of HCTZ for management of hypercalciuria, his allopurinol dose was increased to $200 \mathrm{mg}$ daily and he was advised to continue electrolyte supplementation.

Table 1. $24 \mathrm{~h}$ urine samples.

\begin{tabular}{|c|c|c|c|c|c|c|}
\hline $\begin{array}{l}24 \text { h Urinary } \\
\text { Parameters }\end{array}$ & January 2018 \#1 & January 2018 \#2 & May 2018 & November 2020 & Reference Range & Units/24 h \\
\hline Volume & 4.11 & 4.15 & 4.07 & 3.7 & $0.5-4$ & $\mathrm{~L}$ \\
\hline Calcium & 327 & 366 & 320 & 269 & $<250$ & $\mathrm{mg}$ \\
\hline Oxalate & 25 & 24 & 22 & 19 & $20-40$ & $\mathrm{mg}$ \\
\hline Citrate & $<62$ & $<62$ & $<61$ & $<55$ & $>450$ & $\mathrm{mg}$ \\
\hline Uric Acid & 0.362 & 0.374 & 0.381 & 0.198 & $<0.800$ & $\mathrm{~g}$ \\
\hline Sodium & 153 & 184 & 201 & 164 & $50-150$ & $\mathrm{mEq} / \mathrm{L}$ \\
\hline $\mathrm{pH}$ & 6.732 & 6.671 & 6.599 & 6.973 & $5.8-6.2$ & \\
\hline $\begin{array}{l}\text { SS calcium } \\
\text { oxalate }\end{array}$ & 2.88 & 2.75 & 2.16 & 2.03 & $6-10$ & RS \\
\hline $\begin{array}{l}\text { SS calcium } \\
\text { phosphate }\end{array}$ & 0.83 & 0.81 & 0.7 & 0.91 & $0.5-2$ & RS \\
\hline SS uric acid & 0.04 & 0.05 & 0.06 & 0.01 & $0-1$ & RS \\
\hline
\end{tabular}

Over the next 26 months, the patient had a total of eight ureteroscopic stone procedures to treat his extensive bilateral nephrocalcinosis. At each procedure complete stone clearance was attempted. Given the patients large stone burden, staged procedures were required. Ureteral stents were placed after each procedure and removed after 5 days unless a staged procedure was planned in the future. Of note, the patients most recent ureteroscopies were performed with the thulium fiber laser and, anecdotally, superior stone clearance was noted. Subsequent stone analysis revealed predominantly calcium phosphate (apatite) stones. Throughout this period, the patient continued to have hypercalciuria (269-320 mg/day) and hypomagnesaemia $(1.2 \mathrm{mg} / \mathrm{dL})$ on laboratory evaluations. The patient's $\mathrm{Cr}$ ranged from 2.16 to 2.49 (37-30 eGFR $\left.\mathrm{mL} / \mathrm{min} / 1.73 \mathrm{~m}^{2}\right)$. His serum bicarbonate level ranged from 20 to $27 \mathrm{mmol} / \mathrm{L}$. Most recently, the patient is being managed with chlorthalidone $25 \mathrm{mg}$ daily, amiloride $5 \mathrm{mg}$ in the morning and $10 \mathrm{mg}$ nightly, $1000 \mathrm{mg}$ of calcium supplementation four times a day, magnesium chloride $143 \mathrm{mg}$, and calcitriol $0.25 \mathrm{mg}$ three times a week. He has been followed with renal ultrasounds and kidney-ureter-bladder X-rays every 6-9 months.

Given the constellation of electrolyte abnormalities, urinary metabolic findings, nephrocalcinosis, and childhood onset of symptoms, he was recommended for genetic testing.

\section{Genetic Testing}

The patient underwent genetic testing with a focused 41-gene panel (GeneDx, Gaithersburg, MD, USA) in April 2020. This showed two heterozygous variants in CLDN16: NM_006580.3:c.697G > T - p. (Gly233Cys) and NM_006580.3:c.310G > A - p. (Asp104Asn). The former variant was classified as likely pathogenic and the latter as a VUS following the ACMG/AMP 2015 guidelines [6]. A limitation of the genetic testing is that it cannot determine the phase of the reported CLDN16 variants (cis or trans). Therefore, family variant testing (FVT) was offered to the patient's mother and brother. His mother underwent FVT, 
which confirmed that she carries the likely pathogenic variant and does not carry the VUS. These results, in addition to his clinical presentation, suggest the variants are in trans. The patient's brother has not yet undergone genetic testing.

\section{Discussion}

As our clinical knowledge of FHHNC has grown so has our understanding of its underlying genetic causes. According to the Human Gene Mutation Database, there are 69 genetic variants described in CLDN16 and 22 variants in CLDN19 that have been associated with FHHNC [1,7]. Since FHHNC is inherited in an autosomal recessive manner, affected individuals are homozygous or compound heterozygous for the disease-causing variants. The reported pathogenic variants are located scattered across the gene, so there is no definitive genotype-phenotype correlation; although, individuals with biallelic loss-offunction variants usually progress more rapidly than individuals with missense variants.

The most frequent CLDN16 pathogenic variant is the NM_006580.3:c.453G > T - p. (Leu151Phe) being found in up to 50\% of the Eastern European and German individuals with FHHNC [4,8]. The p. (Gly233Cys) present in the patient reported here is classified as likely pathogenic since it has been reported in trans with other pathogenic variant in families with FHHNC and it is predicted to impact protein function by in silico tools-such as the combined annotation-dependent depletion (CADD) and the rare exome variant ensemble learner (REVEL) [9-11]. Furthermore, there are other pathogenic variants at the same amino acid that have been associated with the disease.

Interestingly, the p. (Asp104Asn) was classified as a VUS by the clinical laboratory due to lack of evidence of pathogenicity. The variant lies at exon 1, in the first extracellular loop of the protein, a region very conserved throughout evolution. It is present in only one allele in the Genome Aggregation Database and it is predicted to be damaging by multiple in silico predictors $[12,13]$. Through family variant testing, it was proved that the CLDN16 variants were in trans. Based on the patient's clinical presentation with a longstanding history of nephrolithiasis, gout, recurrent UTIs, early development of CKD, and classical laboratory findings, the VUS could be reclassified as likely pathogenic. Notably, most pathogenic variants reported in CLDN16 are missense located in one of the two extracellular loops, as is the case for the p. (Asp104Asn) identified in this patient [14]. The patient had manifestations of disease in childhood with a protracted course towards severe complications in adulthood. This slower disease progression highlights that the biallelic missense variants may cause partial loss of protein function.

There are currently no guidelines for the specific treatment of FHHNC. Care focuses around medical management to limit the development of profound nephrocalcinosis, with surgical intervention used to keep stone burden at bay. Thiazide diuretics are one of the mainstays of treatment and have demonstrated decreased rates of hypercalciuria; however, their effect on the course of the disease long-term has not been determined [4]. In our patient, treatment with thiazides did produce a significant change in hypercalciuria levels-demonstrating the variability in treatment response among patient with FHHNC. Hypomagnesemia, and other electrolyte abnormalities, are treated with supplementation. Amiloride may also play a role in treating patients with FHHNC; however, the mechanism of magnesium conservation with the use of the potassium-sparing diuretic is not understood. The patient also suffered from profound hypocitraturia; however, in the context of his stone composition and urinary $\mathrm{pH}$, supplementation with citrate may have increased his risk of stone precipitation. Such competing considerations are common in patients with FHHNC and provide challenges in optimizing their medical management.

Despite optimal supplementation therapy, it is not uncommon for patients to require surgical intervention to address profound nephrocalcinosis. At present, our patient still has a significant stone burden despite multiple stone procedures. The development of advanced laser technology may offer opportunities for more efficient ureteroscopic procedures in the future [15]. The goals of disease management are ultimately to delay the development of 
renal failure. For those that do progress, renal transplantation is an effective option and has shown to resolve electrolyte abnormalities with no evidence of disease recurrence [14,16].

The etiology for renal deterioration in FHHNC patients has not been elucidated. Possible explanations include the effects of prolonged nephrocalcinosis, inflammation secondary to crystal nephropathy or renal dysplasia due to defective claudin-16 function $[14,17,18]$. The patient reported here has had a protracted decline which may be explained by a partial loss of function mutation, as prior studies have noted a more rapid decline when complete loss of function is seen [8]. Without an exact etiology for renal decline, management must focus on treatable sequalae.

\section{Conclusions}

In summary, we have examined the clinical course, diagnosis, and treatment of a middle-aged man with FHHNC. Genetic testing found a novel variant, c.310G > A - p. (Asp104Asn), that is likely pathogenic and may produce partial loss of function of CLND16. The treatment of FHHNC is complex and currently directed by best practices-utilizing both medical and surgical options. As more is understood about FHHNC and the reasons for progression to renal failure are clarified, future treatments may be better tailored.

Author Contributions: Conceptualization, M.H. (Mitchell Humphreys), M.K., K.S.; methodology, M.H. (Mitchell Humphreys), M.K., K.S.; writing—original draft preparation, G.N., T.S., J.M., M.H. (Megan Hager), F.P.eV.; writing—review and editing, G.N., T.S., J.M., M.H. (Megan Hager), F.P.eV.; supervision, M.H. (Mitchell Humphreys), M.K., K.S. All authors have read and agreed to the published version of the manuscript.

Funding: This research received no external funding.

Institutional Review Board Statement: Ethical review and approval were waived for this study after consultation with our institutional ethics committee per institutional guidelines.

Informed Consent Statement: Following institutional guidelines, the patient filled out a release of information form and provided verbal consent for this case report.

Conflicts of Interest: The authors declare no conflict of interest.

\section{References}

1. Deeb, A.; Abood, S.A.; Simon, J.; Dastoor, H.; Pearce, S.H.; Sayer, J.A. A novel CLDN16 mutation in a large family with familial hypomagnesaemia with hypercalciuria and nephrocalcinosis. BMC Res. Notes 2013, 6, 527. [CrossRef] [PubMed]

2. Yamaguti, P.M.; dos Santos, P.A.; Leal, B.S.; Santana, V.B.; Mazzeu, J.F.; Acevedo, A.C.; Neves Fde, A. Identification of the first large deletion in the CLDN16 gene in a patient with FHHNC and late-onset of chronic kidney disease: Case report. BMC Nephrol. 2015, 16, 92. [CrossRef] [PubMed]

3. Prot-Bertoye, C.; Houillier, P. Claudins in Renal Physiology and Pathology. Genes 2020, 11, 290. [CrossRef] [PubMed]

4. Sikora, P.; Zaniew, M.; Haisch, L.; Pulcer, B.; Szczepanska, M.; Moczulska, A.; Rogowska-Kalisz, A.; Bienias, B.; Tkaczyk, M.; Ostalska-Nowicka, D.; et al. Retrospective cohort study of familial hypomagnesaemia with hypercalciuria and nephrocalcinosis due to CLDN16 mutations. Nephrol. Dial. Transpl. 2015, 30, 636-644. [CrossRef] [PubMed]

5. Tasic, V.; Dervisov, D.; Koceva, S.; Weber, S.; Konrad, M. Hypomagnesemia with hypercalciuria and nephrocalcinosis: Case report and a family study. Pediatr. Nephrol. 2005, 20, 1003-1006. [CrossRef] [PubMed]

6. Richards, S.; Aziz, N.; Bale, S.; Bick, D.; Das, S.; Gastier-Foster, J.; Grody, W.W.; Hegde, M.; Lyon, E.; Spector, E.; et al. Standards and guidelines for the interpretation of sequence variants: A joint consensus recommendation of the American College of Medical Genetics and Genomics and the Association for Molecular Pathology. Genet. Med. 2015, 17, 405-424. [CrossRef]

7. Stenson, P.D.; Mort, M.; Ball, E.V.; Chapman, M.; Evans, K.; Azevedo, L.; Hayden, M.; Heywood, S.; Millar, D.S.; Phillips, A.D.; et al. The Human Gene Mutation Database $(\operatorname{HGMD}((\mathrm{R})))$ : Optimizing its use in a clinical diagnostic or research setting. Hum. Genet. 2020, 139, 1197-1207. [CrossRef] [PubMed]

8. Konrad, M.; Hou, J.; Weber, S.; Dotsch, J.; Kari, J.A.; Seeman, T.; Kuwertz-Broking, E.; Peco-Antic, A.; Tasic, V.; Dittrich, K.; et al. CLDN16 genotype predicts renal decline in familial hypomagnesemia with hypercalciuria and nephrocalcinosis. J. Am. Soc. Nephrol. 2008, 19, 171-181. [CrossRef] [PubMed]

9. Rentzsch, P.; Witten, D.; Cooper, G.M.; Shendure, J.; Kircher, M. CADD: Predicting the deleteriousness of variants throughout the human genome. Nucleic. Acids Res. 2019, 47, D886-D894. [CrossRef] [PubMed] 
10. Ioannidis, N.M.; Rothstein, J.H.; Pejaver, V.; Middha, S.; McDonnell, S.K.; Baheti, S.; Musolf, A.; Li, Q.; Holzinger, E.; Karyadi, D.; et al. REVEL: An Ensemble Method for Predicting the Pathogenicity of Rare Missense Variants. Am. J. Hum. Genet. 2016, 99, 877-885. [CrossRef] [PubMed]

11. Kang, J.H.; Choi, H.J.; Cho, H.Y.; Lee, J.H.; Ha, I.S.; Cheong, H.I.; Choi, Y. Familial hypomagnesemia with hypercalciuria and nephrocalcinosis associated with CLDN16 mutations. Pediatr. Nephrol. 2005, 20, 1490-1493. [CrossRef] [PubMed]

12. Wang, Q.; Pierce-Hoffman, E.; Cummings, B.B.; Alfoldi, J.; Francioli, L.C.; Gauthier, L.D.; Hill, A.J.; O’Donnell-Luria, A.H.; Genome Aggregation Database Production, T.; Genome Aggregation Database, C.; et al. Landscape of multi-nucleotide variants in 125,748 human exomes and 15,708 genomes. Nat. Commun. 2020, 11, 2539. [CrossRef] [PubMed]

13. Karczewski, K.J.; Francioli, L.C.; Tiao, G.; Cummings, B.B.; Alfoldi, J.; Wang, Q.; Collins, R.L.; Laricchia, K.M.; Ganna, A.; Birnbaum, D.P.; et al. The mutational constraint spectrum quantified from variation in 141,456 humans. Nature 2020, 581, 434-443. [CrossRef] [PubMed]

14. Claverie-Martin, F. Familial hypomagnesaemia with hypercalciuria and nephrocalcinosis: Clinical and molecular characteristics. Clin. Kidney J. 2015, 8, 656-664. [CrossRef] [PubMed]

15. Martov, A.; Ergakov, D.; Guseynov, M.; Andronov, A.; Plekhanova, O.A. Clinical Comparison of Super Pulse Thulium Fiber Laser and High-Power Holmium Laser for Ureteral Stone Management. J. Endourol. 2020. [CrossRef]

16. Hanssen, O.; Castermans, E.; Bovy, C.; Weekers, L.; Erpicum, P.; Dubois, B.; Bours, V.; Krzesinski, J.M.; Jouret, F. Two novel mutations of the CLDN16 gene cause familial hypomagnesaemia with hypercalciuria and nephrocalcinosis. Clin. Kidney J. 2014, 7, 282-285. [CrossRef] [PubMed]

17. Garcia-Castano, A.; Perdomo-Ramirez, A.; Vall-Palomar, M.; Ramos-Trujillo, E.; Madariaga, L.; Ariceta, G.; Claverie-Martin, F. Novel compound heterozygous mutations of CLDN16 in a patient with familial hypomagnesemia with hypercalciuria and nephrocalcinosis. Mol. Genet. Genom. Med. 2020, 8, e1475. [CrossRef]

18. Lee, D.B.; Huang, E.; Ward, H.J. Tight junction biology and kidney dysfunction. Am. J. Physiol. Ren. Physiol. 2006, 290, F20-F34. [CrossRef] [PubMed] 